Check for updates

Cite this: RSC Adv., 2017, 7, 19604

Received 23rd January 2017

Accepted 18th March 2017

DOI: 10.1039/c7ra01009e

rsc.li/rsc-advances

\title{
Near infrared laser-controlled drug release of thermoresponsive microgel encapsulated with $\mathrm{Fe}_{3} \mathrm{O}_{4}$ nanoparticles
}

\begin{abstract}
Xiaofang $\mathrm{Qi}^{\mathrm{ab}}{ }^{\mathrm{b}}$ Lu Xiong, ${ }^{\mathrm{b}}$ Jing Peng ${ }^{\mathrm{b}}$ and Dongyan Tang (DD *ab
One major issue in thermosensitive drug delivery systems is the remote, repeatable control of temperature in vivo through external stimuli such as light, ultrasound, and magnetic field. In this study, an $\mathrm{Fe}_{3} \mathrm{O}_{4} /$ p(NIPAM-CO-MAA) composite microgel (Nms) was fabricated via copolymerizing NIPAM with MAA in water-containing $\mathrm{Fe}_{3} \mathrm{O}_{4}$ nanoparticles modified by oleic acid. The photothermal effect and thermalresponsibility of $\mathrm{Nms}$ were investigated by adjusting the amount of $\mathrm{MAA}$ and $\mathrm{Fe}_{3} \mathrm{O}_{4}$ in the reaction, and the result shows an LCST of $37.2{ }^{\circ} \mathrm{C}$, which could be elevated to $45.8{ }^{\circ} \mathrm{C}$ under laser treatment at $808 \mathrm{~nm}$. In the drug release experiment, the data show that the drug can be released at an expected rate by controlling the temperature using an $808 \mathrm{~nm}$ laser irradiation in vivo. The release rate was fast and the final cumulative drug release rate increased by about 25\%. Thus, these properties of the $\mathrm{Fe}_{3} \mathrm{O}_{4} /$ p(NIPAM-CO-MAA) Nms microgel indicate its promising application in multi-responsive microgels, especially in photothermal drug carriers.
\end{abstract}

\section{Introduction}

Stimuli-responsive microgels have been well-studied and widely applied in many fields such as tissue engineering, biomedical implants, ${ }^{1}$ drug delivery, ${ }^{2}$ and bionanotechnology, ${ }^{3}$ owing to their three-dimensional (3D) physical structure, ${ }^{4}$ good mechanical properties, ${ }^{5}$ and high water content. ${ }^{6}$ Especially, thermal-responsive microgels based on $\operatorname{poly}(N$-isopropylacrylamide) (PNIPAM) exhibit a lower critical solution temperature (LCST) at about $32^{\circ} \mathrm{C},{ }^{7}$ which is approximate to the physiological temperature of the human body. ${ }^{8}$ Moreover, when the surrounding temperature increases, polymeric microgels undergo a phase transformation from a swollen structure to collapse aggregation, ${ }^{9}$ which provides an opportunity to load and/or release small molecules and thus potential application in cancer therapy.

However, once heated, PNIPAM microgels collapse from the swollen gel in an uncontrollable way, which limits its application in drug-controlled release. Some other stimuli such as $\mathrm{pH}$ (AAc), ${ }^{10}$ oxidoreduction (GSH), ${ }^{11}$ and near-infrared (NIR) light $(\mathrm{CuS})^{12}$ were introduced to adjust the drug release rate. Among all these strategies, NIR absorbing materials can be used as a photothermal ablation agency by transforming light into thermal energy ${ }^{13}$ to kill cancer cells or release drugs. ${ }^{14}$ NIR

${ }^{a}$ State Key Laboratory of Urban Water Resource and Environment, Harbin Institute of Technology, Harbin 150090, China. E-mail: xiaofangqixiao@163.com; dytang@hit. edu.cn

${ }^{b}$ School of Chemistry and Chemical Engineering, Harbin Institute of Technology, Harbin 150001, China photothermal semiconductor nanocystals such as $\operatorname{MoS}_{2},{ }^{13}$ $\mathrm{WS}_{2},{ }^{15}$ and $\mathrm{Cu}_{9} \mathrm{~S}_{5}$ (ref. 16) have become popular because they are inexpensive and readily available. However, some researchers have reported that the potential toxicity, ${ }^{17}$ undegradability, ${ }^{18}$ and low hemolytic activity ${ }^{16}$ impair their application in biomedicine to some extent. Although $\mathrm{Fe}_{3} \mathrm{O}_{4}$ nanoparticles could avoid these problems and effectively absorb NIR light, and have been clinically applied in hyperthermia cancer therapy using NIR, ${ }^{19}$ poor dispersion stability and easy aggregation usually lead to low activity of $\mathrm{Fe}_{3} \mathrm{O}_{4}$ nanoparticles. ${ }^{10}$ One way to overcome these disadvantages is to put them in a polymeric microgel for the stabilization of $\mathrm{Fe}_{3} \mathrm{O}_{4}$ nanoparticles. Moreover, the composite microgel would not only exhibit stronger NIR light absorption but also achieve excellent controlled drug release by adjusting the NIR irradiation power.

Additionally, some similar systems including $\mathrm{Au} @ \mathrm{SiO}_{2} /$ P(NIPAM-co-AAc),${ }^{14}$ PANI/PNIPAM/HPC, ${ }^{11}$ and rNGO@mSiO ${ }_{2} @-$ pNIPAM-co-pAAm ${ }^{12}$ have been reported. Inspired by these composite systems and the related assembly methods, we prepared an $\mathrm{Fe}_{3} \mathrm{O}_{4} / \mathrm{p}$ (NIPAM-co-MAA) microgel by compositing a layer of PNIPAM on the surface of $\mathrm{Fe}_{3} \mathrm{O}_{4}$ nanoparticles. As shown in Fig. 1, we first synthesized $\mathrm{Fe}_{3} \mathrm{O}_{4}$ nanoparticles modified with oleic acid. After this, the nanoparticles were copolymerized with NIPAM and MAA monomers via polymerization in an emulsion. Finally, the photothermal effect and thermal-responsibility of $\mathrm{Fe}_{3} \mathrm{O}_{4} / \mathrm{p}$ (NIPAM-co-MAA) were investigated by determining its drug control release capacity under $808 \mathrm{~nm}$ laser irradiation. The irradiation results indicate that the composite microgel could increase the temperature from 30 to $45.8{ }^{\circ} \mathrm{C}$ and the cumulative drug released amount increased by 


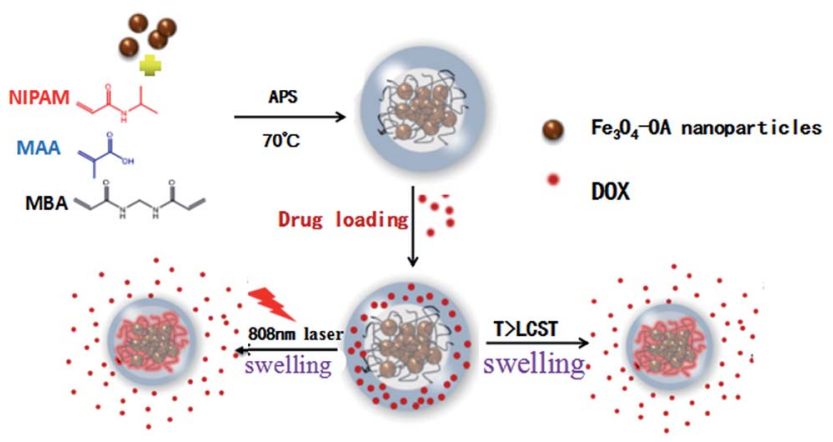

Fig. 1 Schematic for the preparation process and NIR light-triggered drug release of $\mathrm{Fe}_{3} \mathrm{O}_{4} / \mathrm{p}(\mathrm{NIPAM}-\mathrm{CO}-\mathrm{MAA}) \mathrm{Nms}$.

about $25 \%$. The results suggest that the composite microgel Nms exhibits great advantages for photothermal/ chemotherapy. ${ }^{19}$

\section{Experimental}

\subsection{Materials}

Ferric chloride hexahydrate $\left(\mathrm{FeCl}_{3} \cdot 6 \mathrm{H}_{2} \mathrm{O}\right)$, ferrous chloride tetrahydrate $\left(\mathrm{FeCl}_{2} \cdot 4 \mathrm{H}_{2} \mathrm{O}\right)$, ammonia water $\left(\mathrm{NH}_{3} \cdot \mathrm{H}_{2} \mathrm{O}\right)$, oleic acid (OA), doxorubicin (DOX), absolute ethyl alcohol, sodium hydrogen phosphate $\left(\mathrm{Na}_{2} \mathrm{HPO}_{4}\right)$, sodium chloride $(\mathrm{NaCl})$, and isopropyl alcohol were purchased from Xilong Chemical Co., Ltd (Guangdong, China) and used without any further purification. $N$-isopropylacrylamide (NIPAM), methacrylic acid (MAA), ammonium persulfate (APS), $N, N$-methylene bisacrylamide (MBA), and sodium dodecyl sulphate (SDS) were all analytically pure and were purchased from Aladdin Co., Ltd.

\subsection{Synthesis of $\mathrm{OA}$-modified $\mathrm{Fe}_{3} \mathrm{O}_{4}$ nanoparticles}

$\mathrm{Fe}_{3} \mathrm{O}_{4}$ nanoparticles were synthesized by the co-precipitation of iron chloride salts with ammonia. ${ }^{19}$ In a typical synthesis process, ${ }^{20,21} 4.43 \mathrm{~g} \mathrm{FeCl} \cdot 6 \mathrm{H}_{2} \mathrm{O}$ and $1.625 \mathrm{~g} \mathrm{FeCl} \cdot 4 \mathrm{H}_{2} \mathrm{O}$ were dissolved in $190 \mathrm{~mL}$ deionized water under mechanical stirring at $60{ }^{\circ} \mathrm{C}$ under a nitrogen atmosphere. Under the conditions of vigorous stirring, $10 \mathrm{~mL} \mathrm{NH} \mathrm{NH}_{3} \cdot \mathrm{H}_{2} \mathrm{O}$ was poured into the abovementioned solution. After stirring for $30 \mathrm{~min}$, the solution was precipitated by centrifugation and black precipitates obtained were washed three times with ethanol and water. Then, the $\mathrm{Fe}_{3} \mathrm{O}_{4}$ nanoparticles were redispersed in $180 \mathrm{~mL}$ deionized water and heated to $60{ }^{\circ} \mathrm{C}$ under the protection of nitrogen gas, and mixture solutions of $0.9 \mathrm{~g}$ oleic acid and $3 \mathrm{~mL}$ ammonia water were added within $30 \mathrm{~min}$. After this, the solution was heated at $80{ }^{\circ} \mathrm{C}$ and precipitation occurred. The precipitate was washed with acetone 3 times and then dried in a vacuum oven at $70{ }^{\circ} \mathrm{C}$ for $24 \mathrm{~h}$. The $\mathrm{Fe}_{3} \mathrm{O}_{4}$ nanoparticles modified by oleic acid were labelled as $\mathrm{OA}-\mathrm{Fe}_{3} \mathrm{O}_{4}$.

\subsection{Fabrication of P(NIPAM-co-MAA) with OA-modified $\mathrm{Fe}_{3} \mathrm{O}_{4}$ nanoparticles}

The $\mathrm{Fe}_{3} \mathrm{O}_{4} / \mathrm{p}$ (NIPAM-co-MAA) composite microgel was synthesized via a emulsion polymerization method, as previously described. ${ }^{22}$ Herein, $0.5 \mathrm{mg}$ of $\mathrm{OA}-\mathrm{Fe}_{3} \mathrm{O}_{4}$ nanoparticles was mixed with $15 \mathrm{~mL}$ sodium dodecyl sulfate (SDS, $1.0 \mathrm{mg} \mathrm{mL} \mathrm{m}^{-1}$ ) containing $300 \mathrm{mg} N$-isopropylacrylamide (NIPAM, monomer), $15 \mu \mathrm{L}$ methacrylic acid (MAA, monomer), and $10 \mathrm{mg}$ bisacrylamide (MBA, cross-linker). This mixture was vigorously stirred and ultrasonicated, and a brown emulsion was obtained. This mixture was then heated to $70{ }^{\circ} \mathrm{C}$ and bubbled with nitrogen to remove the residual oxygen. Thereafter, $1.0 \mathrm{~mL}$ (10 $\mathrm{mg} \mathrm{mL}^{-1}$ ) ammonium persulfate (APS), as an initiator, was rapidly added, and polymerization was allowed to proceed at $70{ }^{\circ} \mathrm{C}$ for $6 \mathrm{~h}$. Finally, the obtained $\mathrm{Fe}_{3} \mathrm{O}_{4} / \mathrm{p}$ (NIPAM-co-MAA) composite microgel was further purified (Spectra/Por molecular porous membrane tubing, cut-off 12 000-14 $000 \mathrm{Da}$ ), dialyzed for four weeks against very frequently changing water at room temperature $\left(25{ }^{\circ} \mathrm{C}\right)$, and then dried under vacuum at $50{ }^{\circ} \mathrm{C}$. This $\mathrm{Fe}_{3} \mathrm{O}_{4} / \mathrm{p}$ (NIPAM-co-MAA) nanocomposite was labeled as Nms.

\subsection{DOX loading and controlled release from $\mathrm{Fe}_{3} \mathrm{O}_{4} /$ p(NIPAM-co-MAA)}

The composite microgel (24 mg) was dispersed in $10 \mathrm{~mL}$ deionized water. The resulting composite microgel solution was poured into a dialysis bag (cut-off molecular weight of 8000$14000 \mathrm{Da}$ ), the dialysis bag was placed in a $50.0 \mathrm{~mL}$ solution containing the anticancer drug DOX, and then left at room temperature for $24 \mathrm{~h}$. A UV-spectrophotometer was used to measure the transmittance of the dialysate at $480 \mathrm{~nm}$ and to obtain the loading amount according to the DOX standard curve. Moreover, the products were cleaned using deionized water, which was repeated at least five times until a colorless supernatant was obtained.

For photothermal-triggered release, according to Huang's method, ${ }^{22} 1.0 \mathrm{~mL}$ PBS ( $\left.\mathrm{pH}=7.4\right)$ containing Nms@DOX $(1.0 \mathrm{mg}$ $\mathrm{mL}^{-1}$ ) in a $10 \mathrm{~mL}$ test tube was incubated at $37^{\circ} \mathrm{C}$. At predetermined time intervals, the samples were irradiated using an $808 \mathrm{~nm}$ NIR laser with an output power density of $1.0 \mathrm{~W} \mathrm{~cm}-2$ for a certain period of time. The samples were centrifuged (8000 rpm, $10 \mathrm{~min}$ ) and DOX was quantified via UVspectrophotometer analysis using the supernatants. Finally, fresh PBS $(5 \mathrm{~mL})$ was added to the residual mixture.

\subsection{Characterization}

FTIR spectra were obtained at room temperature by a spectrometer (AVATAR 360, Nicolet, USA) and measured in the wavenumber range from 4000 to $400 \mathrm{~cm}^{-1}$ by dispersion in $\mathrm{KBr}$ matrices to elucidate the key structural features. The surface of the composite microgel was observed using a field emission electron microscope (SEM) (Helios Nanolab 600i, FEI, USA) after coating with gold. ${ }^{23}$ Transmission electron microscopy (TEM, JEOL, Japan) images were acquired using a JEOL JEM-1400 TEM operating at the acceleration voltage of $120 \mathrm{kV}$. The thermoresponsive behavior of the composite microgel was investigated using the transmittance of a temperature-controlled UVspectrophotometer (TU-1901, Purkinje, China). Drug release data were monitored using a UV-spectrometer at the wavelength of $480 \mathrm{~nm}$. The light scattering (DLS) size of Nms was measured 
using Zetasizer Nano (Enigma Business Park, Grovewood Road, Malvern, Worcestershire. WR141XZ, United Kingdom). The structures of $\mathrm{OA}-\mathrm{Fe}_{3} \mathrm{O}_{4}$ nanoparticles were identified by XRD (Bruker D8, Bruker AXS, Germany).

\section{Results and discussion}

\subsection{Morphology and structures}

The transmission electron microscopy (TEM) images depicted in Fig. $2 \mathrm{a}$ and $\mathrm{b}$ show that the size of the $\mathrm{OA}-\mathrm{Fe}_{3} \mathrm{O}_{4}$ sample is about $10 \mathrm{~nm}$. Clearly, most of the $\mathrm{Fe}_{3} \mathrm{O}_{4}$ nanoparticles are coated with OA. The higher magnification TEM image (Fig. 2c) reveals that the lattice spacing is $0.253 \mathrm{~nm}$, which is consistent with the $d$ value of the (311) planes of $\mathrm{Fe}_{3} \mathrm{O}_{4}$. In Fig. 2d, the SEM image of the composite microgel Nms-MAA-20, prepared with a MAA comonomer amount of $20 \mu \mathrm{L}$, shows that the sample is a spherical microgel with a diameter of about $400 \mathrm{~nm}$. To further investigate whether $\mathrm{Fe}_{3} \mathrm{O}_{4}$ nanoparticles were successfully coated with the thermosensitive polymer, the composite microgel was observed via TEM (Fig. 2e and f). It was found that the composite microgel had agglomerations with a diameter of about $400 \mathrm{~nm}$, in which the black center denotes the $\mathrm{OA}-\mathrm{Fe}_{3} \mathrm{O}_{4}$ core, whereas the gray layer around the center is the copolymer shell. During the reaction, the existence of electrostatic repulsion between oleic acid and $\mathrm{COO}^{-}$led to unsatisfactory coating of the microgel on the $\mathrm{OA}-\mathrm{Fe}_{3} \mathrm{O}_{4}$ nanoparticles. Through ultrasonication, this situation was obviously improved. As shown in Fig. 2f, $\mathrm{Fe}_{3} \mathrm{O}_{4}$ nanoparticles are encapsulated into microgel with the overall size of about $180 \mathrm{~nm}$ and the thickness of about $80 \mathrm{~nm}$. Therefore, we conclude that the $\mathrm{Fe}_{3} \mathrm{O}_{4}$ nanoparticles were successfully coated with the temperatureresponsive polymer.

The samples with different amounts of $\mathrm{Fe}_{3} \mathrm{O}_{4}$ nanoparticles $(0.5 \mathrm{mg}$ and $5 \mathrm{mg}$ ) are displayed in Fig. 2e and f, respectively, in which obvious differences can be observed. However, it was found that the $\mathrm{Fe}_{3} \mathrm{O}_{4}$ fraction around the composite microgel (Fig. 2f) is relative in the sample with less $\mathrm{Fe}_{3} \mathrm{O}_{4}$ nanoparticles. This suggests that only a few monomers were involved in the
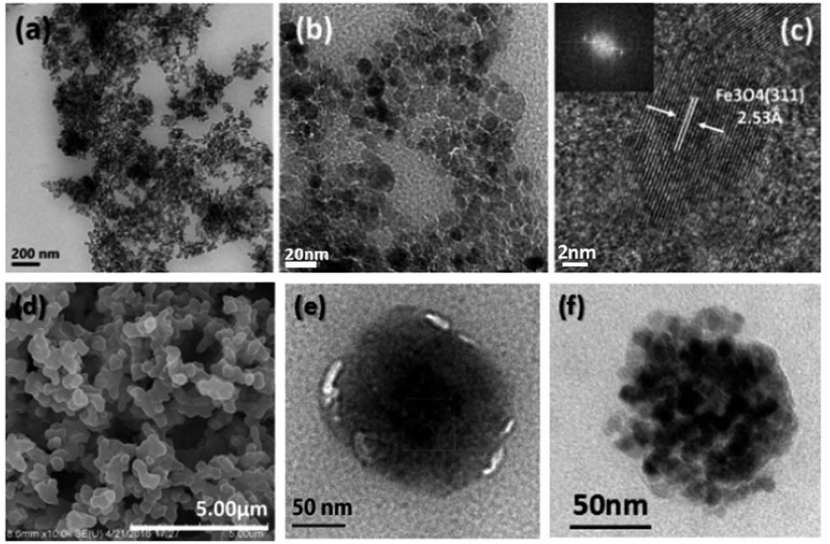

Fig. 2 (a)-(c) TEM images of $\mathrm{OA}-\mathrm{Fe}_{3} \mathrm{O}_{4}$, (d) SEM images of $\mathrm{Nms}$, and (e) and (f) TEM images of $\mathrm{Nms}$ with $0.5 \mathrm{mg}$ and $5 \mathrm{mg} \mathrm{OA}-\mathrm{Fe}_{3} \mathrm{O}_{4}$ nanoparticles, respectively. polymerization reaction, such that a lower content of $\mathrm{Fe}_{3} \mathrm{O}_{4}$ nanoparticles was in the microgel and the $5 \mathrm{mg} \mathrm{Fe}_{3} \mathrm{O}_{4}$ sample reached saturation within the reaction system solution. To further increase the content of $\mathrm{Fe}_{3} \mathrm{O}_{4}$ nanoparticles, the electrostatic interaction between inorganic nanoparticles and polymer microgel could be used in the process of the ultrasound irradiation method ${ }^{25}$ since the prepared $\mathrm{OA}-\mathrm{Fe}_{3} \mathrm{O}_{4}$, initiator APS, and comonomer are charged. Thus, the second capsulation could improve the amount of $\mathrm{Fe}_{3} \mathrm{O}_{4}$ nanoparticles in the composite microgel by ultrasound treatment. As shown in Fig. $3 \mathrm{a}$ and $\mathrm{b}$, the composite microgel containing $0.5 \mathrm{mg}$ of $\mathrm{Fe}_{3} \mathrm{O}_{4}$ nanoparticles was observed by SEM before and after the second capsulation. The results indicate that they have a similar morphology; however, we were unable to determine whether the $\mathrm{Fe}_{3} \mathrm{O}_{4}$ nanoparticles were absorbed into the composite microgel. By investigating the photothermal efficiency of the second capsulation composite microgel, it was observed that the temperature of the composite microgel after the second capsulation exhibited a pronounced increase under an $808 \mathrm{~nm}$ laser irradiation, and the highest elevated temperature was about $42{ }^{\circ} \mathrm{C}$, which is higher than that in the previous capsulation.

\subsection{Characterization of $\mathrm{Fe}_{3} \mathrm{O}_{4}$ and $\mathrm{OA}-\mathrm{Fe}_{3} \mathrm{O}_{4}$ nanoparticles}

3.2.1 VSM. The magnetic properties of the $\mathrm{OA}-\mathrm{Fe}_{3} \mathrm{O}_{4}$ nanoparticles were investigated using a SQUID magnetometer. The $\mathrm{Fe}_{3} \mathrm{O}_{4}$ and $\mathrm{OA}-\mathrm{Fe}_{3} \mathrm{O}_{4}$ hysteresis loops and magnetic optical images are depicted in Fig. 4. This sample exhibited the superparamagnetic behavior of $\mathrm{Fe}_{3} \mathrm{O}_{4}\left(\mathrm{Ms}=70\right.$ emu $\left.\mathrm{g}^{-1}\right)$ and $\mathrm{OA}-\mathrm{Fe}_{3} \mathrm{O}_{4}\left(\mathrm{Ms}=60 \mathrm{emu} \mathrm{g}^{-1}\right)$ due to its near zero coercivity and remanence, which indicate that $\mathrm{OA}-\mathrm{Fe}_{3} \mathrm{O}_{4}$ does not change the magnetism compared with $\mathrm{Fe}_{3} \mathrm{O}_{4}$, and these nanoparticles would be an important candidate for biomedical applications.

3.2.2 XRD. To further ensure the structure of the $\mathrm{OA}-\mathrm{Fe}_{3} \mathrm{O}_{4}$ nanoparticles, its XRD patterns (Fig. 5) were obtained and they matched well with the XRD patterns of the standard spinel type of $\mathrm{Fe}_{3} \mathrm{O}_{4}$ (JCPDS card file no: 19-0629). ${ }^{2}$ The characteristic peaks of $\mathrm{Fe}_{3} \mathrm{O}_{4}$ crystals marked by their indices (220), (311), (400), (422), (440), and (533) can be observed in the patterns of the samples. Compared with $\mathrm{Fe}_{3} \mathrm{O}_{4}$, the peak intensity of $\mathrm{OA}-\mathrm{Fe}_{3} \mathrm{O}_{4}$ remains unchanged, suggesting that the diffraction peaks of the two samples are identical. Furthermore, the result shows that the diffraction peaks of the two samples are all certainly
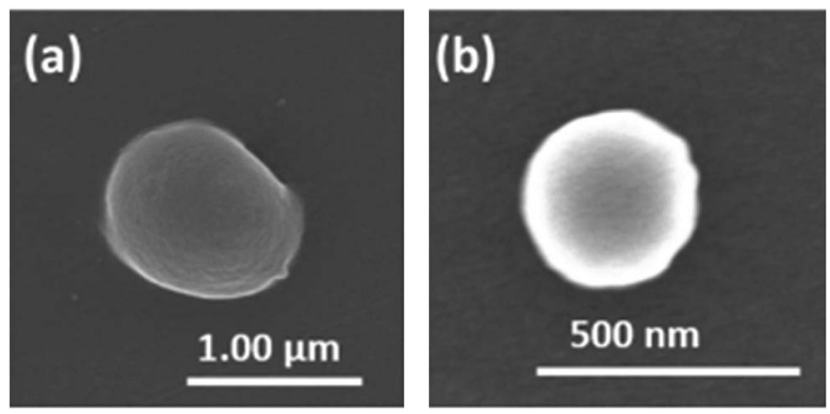

Fig. 3 SEM of Nms (a) before and (b) after the second capsulation. 


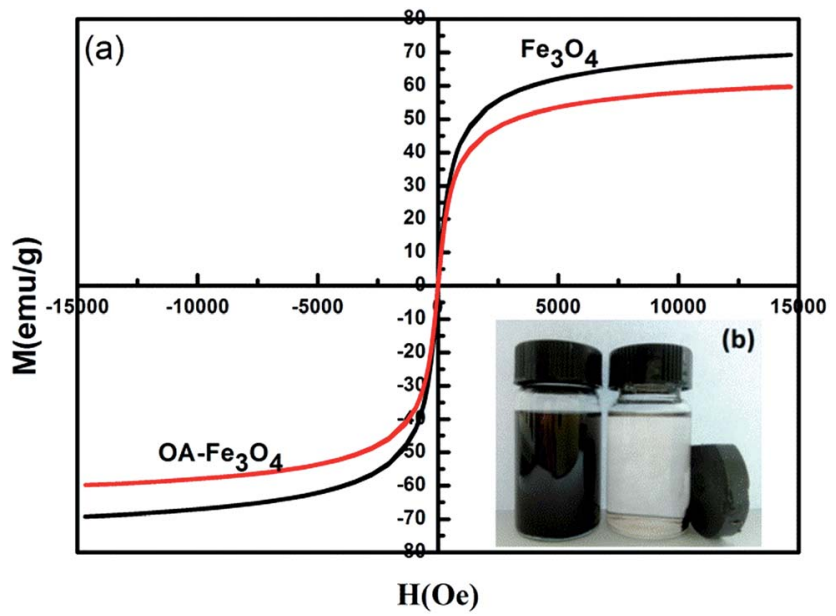

Fig. 4 (a) Magnetic hysteresis loops of $\mathrm{OA}-\mathrm{Fe}_{3} \mathrm{O}_{4}$ and $\mathrm{Fe}_{3} \mathrm{O}_{4}$ and (b) magnetic optical image of $\mathrm{OA}-\mathrm{Fe}_{3} \mathrm{O}_{4}$ and $\mathrm{Fe}_{3} \mathrm{O}_{4}$ nanoparticles.

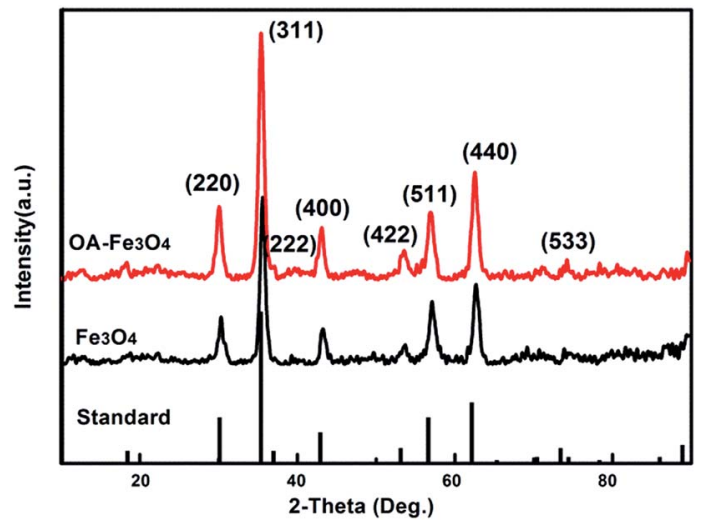

Fig. 5 XRD patterns of $\mathrm{OA}-\mathrm{Fe}_{3} \mathrm{O}_{4}$ and $\mathrm{Fe}_{3} \mathrm{O}_{4}$ nanoparticles.

broadened, and the prepared nanoparticles are smaller in size. However, the average particle sizes are corrected from those obtained via TEM as approximately $127 \mathrm{~nm}$ as a result of the higher crystallinity of the prepared $\mathrm{OA}-\mathrm{Fe}_{3} \mathrm{O}_{4}$ nanoparticles.

\subsection{Characterization of $\mathrm{Fe}_{3} \mathrm{O}_{4} / \mathrm{p}$ (NIPAM-co-MAA)}

The structures of the as-obtained composite microgel Nms and p(NIPAM-co-MAA) microgel were further characterized by Fourier transform infrared (FTIR) spectroscopy (Fig. 6a). The peak at $570 \mathrm{~cm}^{-1}$ is characteristic of the stretching vibrations of Fe-O. The absorption bands at 2976, 2937, and $2877 \mathrm{~cm}^{-1}$ correspond to the symmetric and asymmetric stretching vibrations of $-\mathrm{CH}_{3}$ and $-\mathrm{CH}_{2}$, respectively. In the infrared spectrum of $\mathrm{OA}-\mathrm{Fe}_{3} \mathrm{O}_{4}$, it can be observed that $\mathrm{COO}^{-}$was chemically adsorbed on the surface of $\mathrm{Fe}_{3} \mathrm{O}_{4}$, and the stretching vibration peak was shifted to $1631 \mathrm{~cm}^{-1}$ due to the coupling of $\mathrm{Fe}^{3+}$. Compared with the $\mathrm{p}$ (NIPAM-co-MAA) and Nms curves, the peaks at $369 \mathrm{~cm}^{-1}$ and $1386 \mathrm{~cm}^{-1}$ are the bending vibrations of $-\mathrm{C}\left(\mathrm{CH}_{3}\right)_{2}, 1637 \mathrm{~cm}^{-1}$ and $1548 \mathrm{~cm}^{-1}$ are the characteristic absorption peaks of amide I and amide II, respectively, and the broad absorption peak near $3478 \mathrm{~cm}^{-1}$ occurred due to the overlapping of $-\mathrm{OH}$ and $\mathrm{N}-\mathrm{H}$ bonds. Specifically, the dynamic light scattering (DLS) size of the Nms prepared with $20 \mu \mathrm{L}$ MAA was $318.3 \mathrm{~nm}$ at $25^{\circ} \mathrm{C}$ (Fig. 6b), which is comparable to that reported in earlier studies, ${ }^{24}$ and good dispersion could be observed from the figure without larger or smaller particles. Underwent reversible shrinks and swells, well cycles of these Nms by switching the temperature between $25^{\circ} \mathrm{C}$ and $50^{\circ} \mathrm{C}$ (Fig. 6c) were achieved, suggesting their applicability in long-term stable thermosensitive drug release. To adjust its response to temperature and $\mathrm{pH}$ in cancer-tumor, the hydrophilic and acidic monomer MAA was introduced into the PNIPAM-based microgel. Fig. 6d depicts the LCST measured using a turbidity curve, which shows that the LCST of Nms with the comonomer MAA amounts of $10 \mu \mathrm{L}, 20 \mu \mathrm{L}$, and $30 \mu \mathrm{L}$ was $35.4{ }^{\circ} \mathrm{C}, 37.2{ }^{\circ} \mathrm{C}$, and $38.3{ }^{\circ} \mathrm{C}$, respectively. The LCST of the composite microgel with MAA was higher than that of pure PNIPAM (which was about $32{ }^{\circ} \mathrm{C}$ ). This result indicates that the MAA monomer could increase the LCST of the composite microgel. TG measurement could roughly determine the content of $\mathrm{Fe}_{3} \mathrm{O}_{4}$ nanoparticles in the synthesized microgel. The TG/DTG curves of Nms are shown in Fig. 6e. The DTG derivative curves from room temperature to $690.8^{\circ} \mathrm{C}$ show two distinct transitions for the composite microgel, and the TG curves indicate three weight loss processes ( $\mathrm{Nms}$ lost $\sim 2 \%$ residual water from room temperature to $307.5{ }^{\circ} \mathrm{C} ; \sim 93.8 \%$ due to the decomposition of organic components from $310.5{ }^{\circ} \mathrm{C}$ to $502.6{ }^{\circ} \mathrm{C}$, which suggests the existence of a small amount of $\mathrm{Fe}_{3} \mathrm{O}_{4}$ nanoparticles; and no remarkable weight loss in the range of 502.6-700 ${ }^{\circ} \mathrm{C}$, which suggests the remaining $\mathrm{Fe}_{3} \mathrm{O}_{4}$ nanoparticles of about $0.36 \%$ )

\subsection{Photothermal conversion of $\mathrm{OA}-\mathrm{Fe}_{3} \mathrm{O}_{4}$ and $\mathrm{Fe}_{3} \mathrm{O}_{4} /$ p(NIPAM-co-MAA)}

The $\mathrm{OA}-\mathrm{Fe}_{3} \mathrm{O}_{4}$ nanoparticles within an aqueous suspension show a broad and continuous absorption spectrum ${ }^{19}$ and the NIR absorption intensity increased with the concentration of $\mathrm{OA}-\mathrm{Fe}_{3} \mathrm{O}_{4}$ nanoparticles (Fig. 7a). The photothermal conversion effect was also initially studied on dry $\mathrm{OA}-\mathrm{Fe}_{3} \mathrm{O}_{4}$ nanoparticle powders, which were exposed to an $808 \mathrm{~nm}$ laser irradiation at a relatively low power density $\left(1 \mathrm{~W} \mathrm{~cm}^{-2}\right.$ ) (Fig. $\left.7 \mathrm{~b}\right)$. The heating curves of these solutions were similar to those of $\mathrm{OA}-\mathrm{Fe}_{3} \mathrm{O}_{4}$ nanoparticles and showed rapid heating and large temperature increments depending on the concentrations. The photothermal effects of the $\mathrm{Fe}_{3} \mathrm{O}_{4} / \mathrm{p}$ (NIPAM-co-MAA) Nms solution with different amounts of $\mathrm{OA}-\mathrm{Fe}_{3} \mathrm{O}_{4}$ nanoparticles at 0.5, 3.0, and $5.0 \mathrm{mg}$ were exposed to an $808 \mathrm{~nm}$ NIR laser irradiation at the power density of $1.0 \mathrm{~W} \mathrm{~cm}^{-2}$ for $5 \mathrm{~min}$ (Fig. 8). In contrast to water, Nms showed a concentration-dependent temperature increase. We also clearly observed similar temperature increase processes of Nms at different points of times, which could be directly attributed to the efficient absorption of the $808 \mathrm{~nm}$ NIR laser irradiation by Nms. The photothermal conversion efficiency could reach up to $\sim 30 \%$. After this, the photothermal efficiency of the composite microgel after second capsulation was found to increase under the $808 \mathrm{~nm}$ laser irradiation (Fig. 9a), and the highest elevated temperature was about $42{ }^{\circ} \mathrm{C}$, which is higher than that in the previous capsulation. Moreover, the composite microgels with $0.5 \mathrm{mg}$ and $5.0 \mathrm{mg} \mathrm{Fe}_{3} \mathrm{O}_{4}$ 

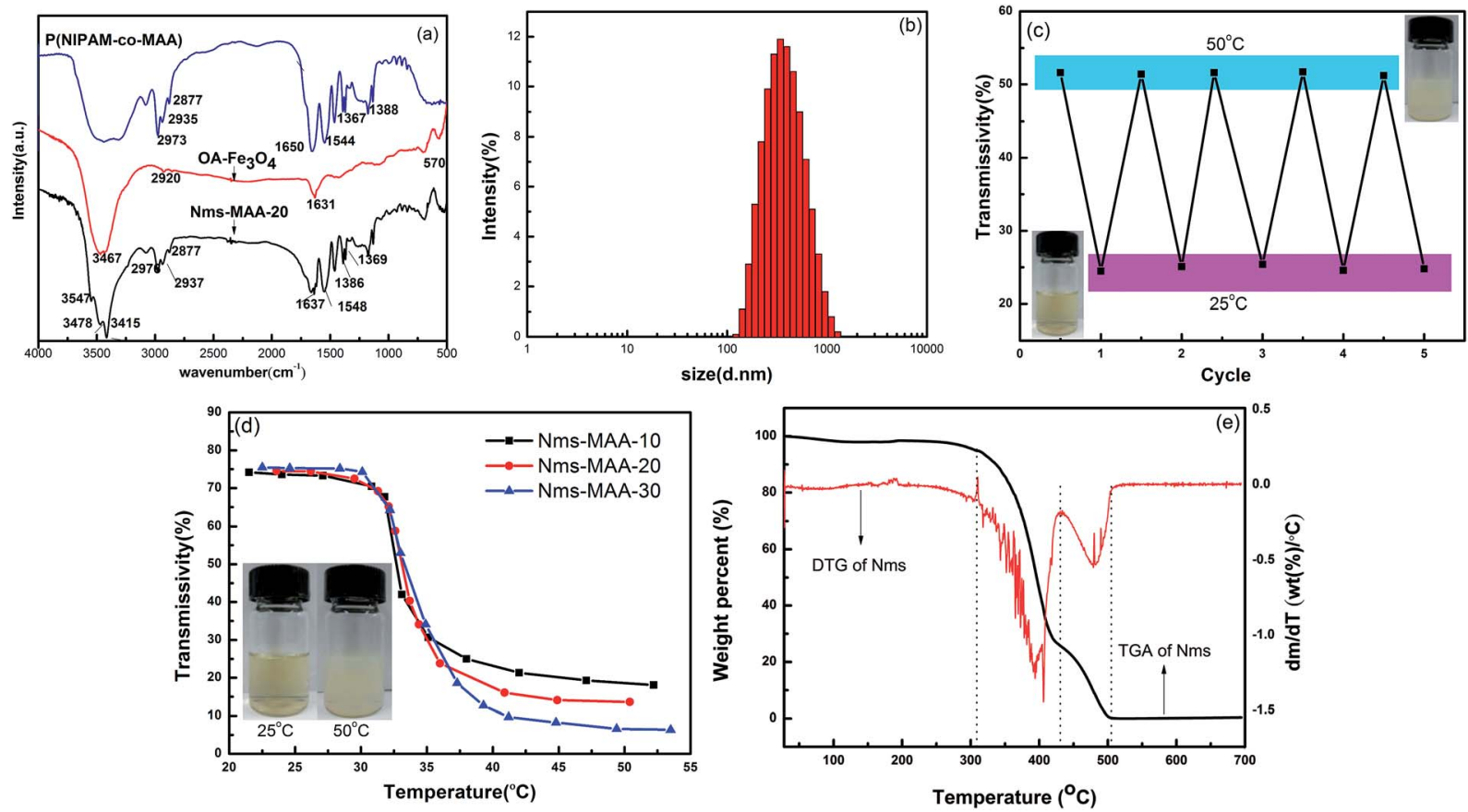

Fig. 6 (a) FT-IR spectra of $\mathrm{p}\left(\mathrm{NIPAM}-\mathrm{CO}-\mathrm{MAA}\right.$ ), OA- $\mathrm{Fe}_{3} \mathrm{O}_{4}$, and Nms, (b) DLS size and distribution of Nms, (c) transmissivity change of Nms by switching the temperature between 25 and $50^{\circ} \mathrm{C}$, (d) LCST of Nms by testing the change in transmissivity with temperature, and (e) TGA and DTG of Nms.
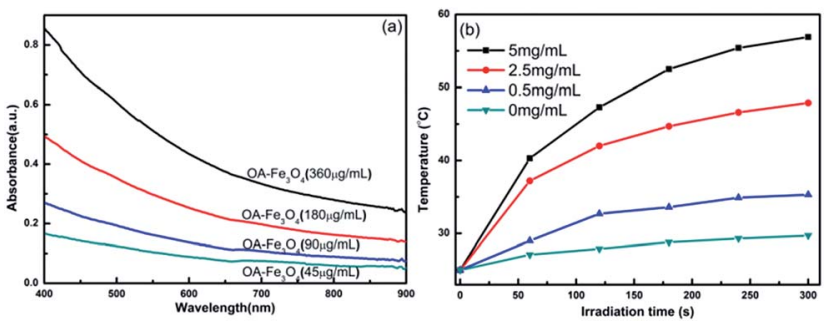

Fig. 7 (a) UV-vis absorption spectra of $\mathrm{OA}-\mathrm{Fe}_{3} \mathrm{O}_{4}$ nanoparticles at different concentrations and (b) temperature evaluation of $\mathrm{OA}-\mathrm{Fe}_{3} \mathrm{O}_{4}$ nanoparticles at different concentrations under $808 \mathrm{~nm}$ laser irradiation for $5 \mathrm{~min}$.

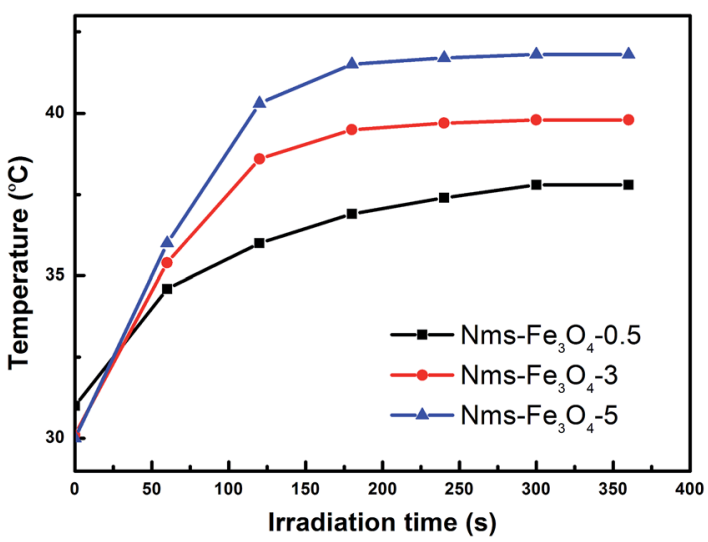

Fig. 8 Temperature evaluation of Nms with different amounts of OA$\mathrm{Fe}_{3} \mathrm{O}_{4}$ under an $808 \mathrm{~nm}$ laser irradiation for $5 \mathrm{~min}$. nanoparticles, obtained through second capsulation, were irradiated under the $808 \mathrm{~nm}$ laser irradiation (Fig. 9b). The composite microgel with $5.0 \mathrm{mg} \mathrm{Fe}_{3} \mathrm{O}_{4}$ nanoparticles obtained through second capsulation had significantly higher photothermal efficiency as compared to the former, and the temperature could reach up to $45.8{ }^{\circ} \mathrm{C}$ within 5 min under an irradiation power density of $1.0 \mathrm{~W} \mathrm{~cm}{ }^{-2}$. Therefore, all our outcomes reveal that the optimized $\mathrm{Fe}_{3} \mathrm{O}_{4} / \mathrm{p}$ (NIPAM-co-MAA) Nms displays excellent photothermal conversion efficiency, which is favorable for controlled photo-thermosensitive drug release.

\subsection{NIR photothermally controlled drug release}

Encouraged by the excellent photothermal properties of Nms, DOX (a drug model) was loaded into Nms via electrostatic interaction and hydrogen bonds. The quantitative analysis of DOX as a result of drug release was studied using different concentrations of DOX standard solutions, and the transmittance of a UV-vis spectrophotometer was used at the wavenumber of $480 \mathrm{~nm}$. The different concentrations of DOX in aqueous solutions following the Lambert-Beer law are presented in Fig. 10a, and the $R^{2}$ value of the fitted curve is 0.997 . Then, the cumulative release rate was investigated. Details of the analysis include incubation of the DOX-loaded composite microgels in a PBS solution at $\mathrm{pH} 7.4$ and keeping the samples at $30^{\circ} \mathrm{C}$ for $1 \mathrm{~h}$ before the release. The DOX concentration was measured every $30 \mathrm{~min}$ and the $808 \mathrm{~nm}$ laser irradiation was turned on and the samples were irradiated at the power density of $1.0 \mathrm{~W} \mathrm{~cm}^{-2}$. The sample was analyzed after 10 minutes, and the abovementioned steps were repeated until the DOX concentration was not 

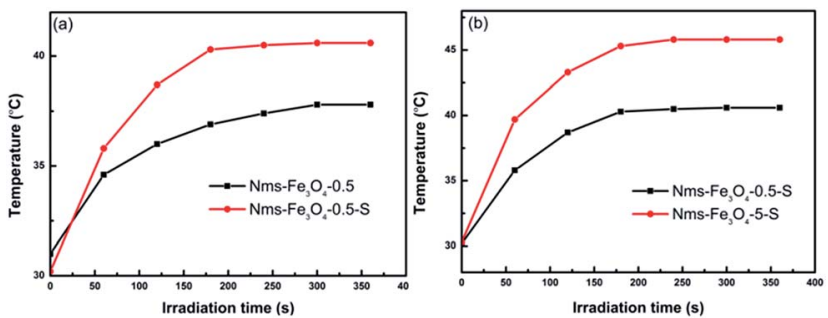

Fig. 9 (a) Temperature evaluation of $\mathrm{Nms}$ at an $\mathrm{OA}-\mathrm{Fe}_{3} \mathrm{O}_{4}$ content of $0.5 \mathrm{mg}$ before and after the second capsulation under an $808 \mathrm{~nm}$ laser irradiation for $5 \mathrm{~min}$ and (b) temperature evaluation of $\mathrm{Nms}$ with different amounts of $\mathrm{OA}-\mathrm{Fe}_{3} \mathrm{O}_{4}$ under an $808 \mathrm{~nm}$ laser irradiation for 5 min by second capsulation.
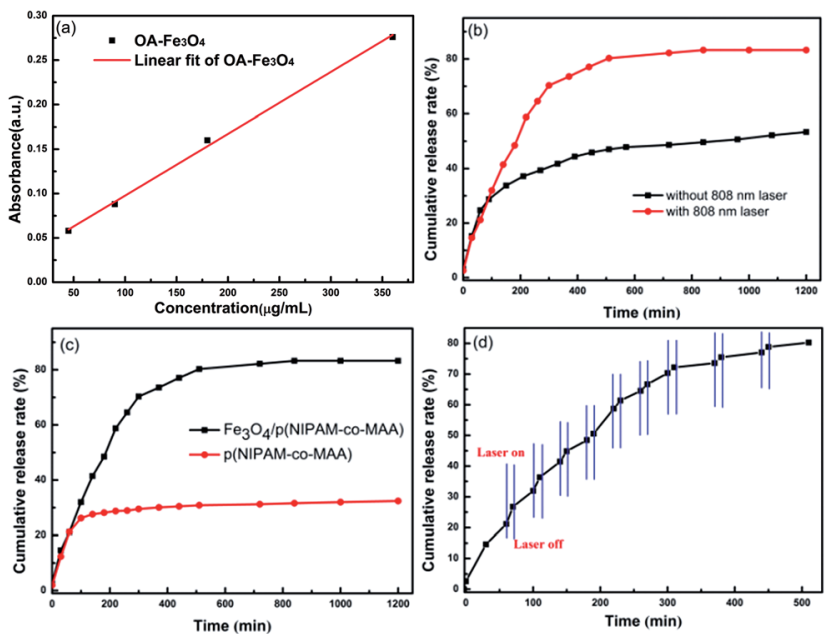

Fig. 10 (a) Standard curve of DOX, (b) DOX cumulative release with time under dark conditions and an $808 \mathrm{~nm}$ laser irradiation, (c) DOX cumulative release of $\mathrm{p}(\mathrm{NIPAM}-\mathrm{CO}-\mathrm{MAA})$ and $\mathrm{Fe}_{3} \mathrm{O}_{4} / \mathrm{p}$ (NIPAM-COMAA) with time under an $808 \mathrm{~nm}$ laser irradiation, and (d) DOX cumulative release with time by on/off $808 \mathrm{~nm}$ laser irradiation.

significantly increased. The cumulative release rate formula (equation) could be represented as follows:

$$
\text { cumulative release rate }=\frac{v_{1} \times c_{i}+v_{2} \sum c_{(i-1)}}{m} \times 100 \%
$$

where $v_{1}$ is the total volume of the PBS solution $(200 \mathrm{~mL})$, $c_{i}$ is the concentration of the drug in the PBS solution, $v_{2}$ is the volume of the sample ( $3 \mathrm{~mL})$, and $m$ is the total quality of the composite microgel. The calculated total amount of DOX loading within $24 \mathrm{mg}$ composite microgel was $3.7 \mathrm{mg}$. As shown in Fig. 10b, the slow drug release of the composite microgels at $30{ }^{\circ} \mathrm{C}$ was investigated under dark conditions and an $808 \mathrm{~nm}$ laser irradiation. The cumulative release rate of the drug-loaded microgel under an $808 \mathrm{~nm}$ laser irradiation is faster than that without laser irradiation. The two curves indicate that DOX was quickly released in the first $5 \mathrm{~h}$, then gradually released, and finally there was no obvious drug release after $16 \mathrm{~h}$ (within the PBS solution at the $\mathrm{pH}$ value of 7.4). The drug release of the composite microgel was tested under an $808 \mathrm{~nm}$ laser, as shown in Fig. 10b and c. The composite microgel containing $\mathrm{Fe}_{3} \mathrm{O}_{4}$ nanoparticles without the irradiation of the $808 \mathrm{~nm}$ laser only released about $40 \%$ of the drug, which is far lower than that by the composite microgel irradiated with the $808 \mathrm{~nm}$ laser (Fig. 10b). In the $\mathrm{Fe}_{3} \mathrm{O}_{4} / \mathrm{p}$ (NIPAM-co-MAA) microgel, $\mathrm{Fe}_{3} \mathrm{O}_{4}$ nanoparticles works as the photothermal agent and could transform light into thermal energy to increase the temperature of the composite microgel upon laser irradiation. However, the microgel without $\mathrm{Fe}_{3} \mathrm{O}_{4}$ nanoparticles could not be affected and changed by $808 \mathrm{~nm}$ laser irradiation, and thus the tiny release amount of drug, as shown in Fig. 10c, is mostly induced from the diffusion effect of the laser. As shown in Fig. 10d, the cumulative release curve of the drug indicates that the drug release rate under the $808 \mathrm{~nm}$ laser irradiation is extremely faster than that in the absence of the laser. Moreover, the final cumulative release rate was about $25 \%$, which is higher than the cumulative release rate without $808 \mathrm{~nm}$ laser irradiation. Thus, we conclude that the prepared composite microgel could absorb NIR light and convert it into heat energy, and the promotion of the drug loaded and released rate are significantly increased under laser irradiation. The increase in the final cumulative release rate originated from the repeated heating and dropping of the composite microgel structure under intermittent $808 \mathrm{~nm}$ laser irradiation, which led to the composite microgel shrinking and swelling, respectively. The high cumulative release rate originated from the shrinking and swelling process of the microgel, which were driven by the intermittent irradiation of the NIR laser.

\section{Conclusion}

In summary, an $\mathrm{Fe}_{3} \mathrm{O}_{4} / \mathrm{p}$ (NIPAM-co-MAA) Nms composite microgel was prepared by the emulsion polymerization of NIPAM and MAA in the presence of $\mathrm{OA}-\mathrm{Fe}_{3} \mathrm{O}_{4}$ nanoparticles. Nms exhibits both photothermal effects and thermo/PH field sensitivities, and its drug release rate could be increased by $25 \%$. Further, after adjusting the amount of MAA, the LCST of the composite microgel could be increased to $37.2^{\circ} \mathrm{C}$ and the temperature of $\mathrm{Nms}$ could be increased to $45.8{ }^{\circ} \mathrm{C}$ under an $808 \mathrm{~nm}$ laser irradiation by the second capsulation method. Due to its good biocompatibility and degradability, $\mathrm{Fe}_{3} \mathrm{O}_{4}$ nanoparticles show great promise in meeting the clinical requirements of mild irradiation and low dosage. Moreover, the magnetic properties of $\mathrm{Fe}_{3} \mathrm{O}_{4}$ nanoparticles could be used to separate proteins and enzymes as well as in nuclear magnetic resonance imaging.

\section{Acknowledgements}

The authors are grateful for the Excellent Academic Leaders Foundation of Harbin, China (No. 2014RFXXJ017), and the Open Project of State Key Laboratory of Urban Water Resource and Environment, Harbin Institute of Technology (No. QA201610-02). 


\section{References}

1 S. S. Aravind, J. Costa, M. Pereira, V. Mugweru, A. Ramanujachary and T. D. Vaden, Int. J. Hydrogen Energy, 2014, 39, 11528-11536.

2 H. Wu, G. P. Liu, Y. Zhuang, D. Wu, H. Zhang, H. Yang and S. Yang, Biomaterials, 2011, 32, 4867-4876.

3 J. K. Oh, R. Drumright, D. J. Siegwart and P. Matyjaszewski, Polym. Sci., 2008, 33, 448-477.

4 A. S. Hoffman, J. Controlled Release, 1987, 6, 297-305.

5 R. Langer and J. P. Vacanti, Science, 1993, 260, 920-926.

6 R. Langer, Science, 2001, 293, 58-59.

7 D. Crespy and R. M. Rossi, Polym. Int., 2007, 56, 1461-1468. 8 M. Ballauff and Y. Lu, Polymer, 2007, 48, 1815-1823.

9 M. Quesada-Pérez, J. A. Maroto-Centeno, J. Forcada and R. Hidalgo-Alvarez, Soft Matter, 2011, 7, 10536.

10 H. Kawaguchi, Polym. Int., 2014, 63, 925-932.

11 S. B. Abel, S. B. Abel, M. A. Molina, C. R. Rivarola, M. J. Kogan and Barbero, Nanotechnology, 2014, 25, 495602.

12 H. Wan, Y. Zhang, Z. Liu, G. Xu, G. Huang, Y. Ji and H. zou, Nanoscale, 2014, 6, 8743-8753.

13 S. S. Chou, B. Kaehr, J. Kim, B. M. Foley, M. De, P. E. Hopkins and V. P. Dravid, Angew. Chem., Int. Ed., 2013, 52, 4160-4170.
14 Z. Zhang, J. Wang, X. R. Nie, T. Wen, Y. Ji, X. Wu and R. Chen, J. Am. Chem. Soc., 2014, 7317-7326.

15 G. S. Song, F. Jiang, R. Hu, W. P. Li and J. Hu, ACS Appl. Mater. Interfaces, 2014, 6, 3915-3922.

16 Q. Tian, F. Z. Jiang, Q. Liu, Z. Chen, M. Zhu and J. Hu, ACS Nano, 2011, 5, 9761-9771.

17 G. Song, Q. Wang, Y. Wang, G. N. Lv, R. Zou and J. Hu, Adv. Funct. Mater., 2013, 23, 4281-4292.

18 Q. Liu, C. Sun, Q. He, D. Liu, A. Khalil, T. Xiang and L. Song, Chem. Commun., 2015, 51, 10054-10057.

19 M. Chu, Y. Shao, J. Peng, X. Dai, H. Li, Q. Wu and D. Shi, Biomaterials, 2013, 34, 4078-4088.

20 A. Bumb, M. W. Brechbiel, P. L. Choyke, L. Fugger and A. Eggeman, Nanotechnology, 2008, 19, 335601.

21 J. Park, K. An, Y. H. Wang, J. G. Park, H. J. Noh, J. Y. Kim and T. Hyeon, Nat. Mater., 2004, 3, 891-895.

22 S. Huang, J. J. Liu, Q. He, H. C. Chen, S. Xu and L. Wang, Nano Res., 2015, 8, 4038-4047.

23 X. L. Lin, D. Y. Tang, Z. Q. Yu and Q. Feng, J. Mater. Chem. B, 2014, 2, 651-658.

24 Y. S. Kang, S. Risbud, J. F. Rabolt and P. Stroeve, Chem. Mater., 1996, 8, 2209-2215.

25 J. Chen, C. Burger, C. V. Krishnan and B. J. Chu, J. Am. Chem. Soc., 2005, 127, 4140-4141. 